\title{
Postgraduate Online Teaching in Healthcare: An Analysis of Student Perspectives
}

\author{
Cuisle Forde and Silvia Gallagher \\ Trinity College Dublin
}

\begin{abstract}
The use of online learning in postgraduate teaching has increased dramatically in recent years. Health-care professionals can benefit from the flexibility afforded by online learning to fulfil their continuing professional development goals. Understanding student expectations, concerns, and experiences of such courses is crucial for the development and successful facilitation of this education modality. The aim of this paper was to examine student perspectives of an online postgraduate certificate in clinical exercise prescription. A set of recommendations based on these findings was also created which may serve to inform those involved in online education.

Students expressed their expectations and concerns about taking the course before it began, and completed surveys on their experience after module completion. A multi-method approach using both qualitative content analysis and quantitative survey analysis was used to analyze student responses on the online modules in the virtual learning environment.

Students $(n=19)$ had a combination of academic, personal, and clinical expectations entering the course. Concerns entering the course included ability to reach academic standards set by the course due to personal circumstances or lack of academic ability; the ability to manage time and workload; and the online nature of the course. Students felt supported throughout the course, although some had difficulties keeping up with the workload or managing their time. Results of this study can be used to inform the structure and coordination of online modules, in particular in the postgraduate healthcare setting.
\end{abstract}

Keywords: online education, postgraduate, recommendations, student perspectives, student support

Forde, C. \& Gallagher, S. (2020). Postgraduate online teaching in healthcare: An analysis of student perspectives. Online Learning, 24(1), 118-139.

https://doi.org/10.24059/olj.v24i1.1566

\section{Postgraduate Online Teaching in Healthcare: An Analysis of Student Perspectives}

Recent years have seen an increase in the number and types of courses in higher education being offered online (Allen et al., 2016). At postgraduate level, online teaching (or e-learning) is particularly suited to healthcare professionals, as they are required to engage in continued professional development (CPD), yet cite time and lack of provision of study leave as barriers to attending traditional face-to-face classes (Haywood et al., 2013a; Haywood et al., 2013b). Many online courses have been developed specifically for healthcare professionals (Brown \& Bullock, 
2014; Field, 2002; Gardner et al., 2016; Murphy et al., 2015; Wolbrink \& Burns, 2012) and this delivery method can help overcome some of the challenges for healthcare education (Ruckert et al., 2014).

As a teaching method, online education in its various forms has been hailed for its potential to promote higher level thinking. This stems from the fact that theory can be learned at a time that suits the student, enabling synchronous and asynchronous interactions between academics and students, to be used for debate, discussions, case scenarios, and problem-solving (Ally, 2004). In general, student and staff acceptance of such courses has been very high, with effective use of financial and time resources as well as effective learning being cited as positive benefits to elearning (Bergold et al., 2013; Fisher, 2015; Gummesson, 2012; Macznik et al., 2015).

However, health-care students have varied perceptions of using information communication technology in relation to education (Costello et al., 2014), and incorporating new pedagogical models can challenge the student learning experience (McDonald et al., 2014). Understanding student perceptions as online learners in health sciences education can help health science educators address students' concerns and expectations, tailor the online modules or information imparted accordingly, and as previous research has shown, can help build more effective online courses (Howland \& Moore, 2002; Song et al., 2004). It can also provide evidence to the wider discipline on the concerns, needs, and expectations of health-care professionals undertaking further education in this space. This can support the development of more online courses and help guide educational and professional institutions in future efforts.

The purpose of this paper was to expand understanding of student perspectives in this field, specifically in health science courses. The main research questions explored in this study were

1. What expectations do health-care students have prior to starting a postgraduate online course?

2. What concerns do health-care students have prior to starting a postgraduate online course?

3. What perceptions and experiences do healthcare students have during and after modules on a postgraduate online course?

Finally, for the information gathered as part of this study to be of most use, it was an aim of the authors to develop a set of recommendations for online educators that would serve as a guide for online course development and facilitation.

\section{Background on the Course and Aims of this Study}

The online Postgraduate Certificate in Clinical Exercise was delivered online over one academic year via four modules with a total of 27 teaching weeks. Teaching included weekly asynchronous lectures (interactive slides with a voice over), weekly synchronous tutorials (webinars), self-directed reading, discussion board posts that were moderated by academic staff, reflective journal entries and multiple-choice questions. Assessment consisted of essays, case scenarios, engagement with online material (equivalent to attendance), and multiple-choice questions. Each module had the same week-by-week structure whereby students began the week with an asynchronous webinar followed by multiple choice questions. Students were then required to carry out a task (e.g., write a reflective journal entry) and the week ended with a synchronous webinar that addressed any issues with the material that were presented during the week and encouraged discussion and debate on the topic at hand. The length of each of the four modules depended on the credits that were attributed to it (in line with the European Credit Transfer and 
Accumulation System) and ranged in length from 10 weeks to 4 weeks. The course had a total of 27 active teaching weeks, one revision week, and three exam weeks. There was a four-week break for Christmas holidays. Students were expected to log in during each active teaching week. In order to gain marks equivalent to attendance, students had to be present during the live webinar and to have engaged with the asynchronous material during the week preceding the live webinar.

The structure of the certificate was determined by staff developing and teaching on the course in collaboration with the online education team at the university. It was considered imperative during the development of the course that there would be both asynchronous and live components and that the students would be required to contribute to the course in the form of a blog post or reflective journal entry during each active teaching week. The main difference between these online learning tools is that a blog post is shared with all members of the class whereas a reflective journal entry is between the academic and student and is not shared with the class. This structure was hoped to encourage continuous engagement with the course material and a high level of learning.

Twenty students registered for the Online Postgraduate Certificate in Clinical Exercise and seventeen students completed the course in 2016. All three students who left the course did so during the first module. The average student age was $35(S D=8)$ years. The youngest was aged 24 and oldest aged 50. Twelve female and eight male students registered for the course. Of these students 12 were physiotherapists, four were nurses, and four were other allied health scientists. All students had English as their mother tongue or had completed a higher intermediate English language exam within the previous 2 years. The majority of the students (18) lived on the island of Ireland (from where the course was being hosted) and were working full time in clinical positions.

As part of the course orientation students were asked to write a short introduction about themselves, to contribute to a discussion board about their expectations of the course, and to write a journal entry about their apprehensions or concerns taking the course. After each module, students were asked to complete a simple feedback survey with five Likert style questions and one open-ended question that served to assess the basic structure of the online modules and whether students believed that it succeeded in meeting learning objectives.

\section{Methods}

This study used both qualitative content analysis and quantitative survey analysis to analyze student contributions in the virtual learning environment (VLE) and post-module surveys. Content analysis is a method for analyzing written, verbal, or visual communication messages (Hsieh \& Shannon, 2005). Its purpose is to produce a condensed description of a phenomenon and to generate concepts used for theoretical categorization (Elo \& Kyngas, 2008). Qualitative data, which included open-ended comments/suggestions from the feedback surveys as well as relevant discussion posts, reflective journal entries, were analyzed using NVivo 11 software (see Table 1). Table 1 outlines data sources for analysis. This software aids qualitative analysis of large amounts of text-based data, and has been successfully used to support similar research (Anaf \& Sheppard, 2010; Lefmann \& Sheppard, 2014; Moore et al., 2003). Text can be coded with themes, and also provides a useful audit trail of the analysis where temporal changes in categorical interpretation and coding can be seen. Thus, NVivo 11 provided the framework for analysis and consolidation of themes. For the qualitative analysis an inductive method was employed. Initially, several broad 
themes were identified relating to our research question (student expectations and concerns), but on further synthesis, more complex themes were integrated into main themes and themes that led to a more concise view of student's experiences. A reflective iterative approach by two researchers facilitated this process. All coding was completed in NVivo 11 and grouped into two categories: "pre-course" and "during course." Codes were compared within the NVivo system software and any differences were resolved through consensus discussion. Any remaining difference were resolved through discussion with a third researcher not directly involved in the study.

All contributions from students were collected after the course was completed and final marks had been awarded. All students provided written informed consent. Ethical approval for this study was granted by the Trinity College Medical Research Committee. Individuals could not be associated with any information given, and this study was designed retrospectively.

\section{Results}

Table 1.

Data Sources for Analysis

\begin{tabular}{lllll}
\hline $\begin{array}{l}\text { Course } \\
\text { period }\end{array}$ & Question posed & $\begin{array}{l}\text { Resource } \\
\text { type }\end{array}$ & $\begin{array}{l}\text { Number of } \\
\text { codable } \\
\text { items }\end{array}$ & $\begin{array}{l}\text { Number } \\
\text { of words }\end{array}$ \\
\hline Pre-course & $\begin{array}{l}\text { What are you most looking forward } \\
\text { to with regard to the course? }\end{array}$ & Blog & 15 & 2,060 \\
Pre-course & $\begin{array}{l}\text { What are your concerns surrounding } \\
\text { taking this course? }\end{array}$ & $\begin{array}{l}\text { Learning } \\
\text { Journal }\end{array}$ & 15 & 1,817 \\
Pre-course & Hello Class Thread & $\begin{array}{l}\text { Discussion } \\
\text { Board } \\
\text { Survey }\end{array}$ & 29 & 2,740 \\
$\begin{array}{l}\text { During } \\
\text { course }\end{array}$ & $\begin{array}{l}\text { Open-ended questions at end of each } \\
\text { module survey }\end{array}$ & \begin{tabular}{l} 
Survey \\
\hline
\end{tabular}
\end{tabular}

A summary of themes and subthemes that emerged from qualitative data analyses are outlined in Table 2. 
Table 2

Themes and Subthemes Emerging from Analyzed Qualitative Data

Temporal period Theme Subtheme

NOTE: Only subthemes with the largest number of coded entries have been included under each theme due to space constraints and to provide a concise representation of data analysis

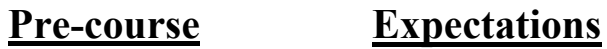

Learning $(n=87)$

Achievements $(n=34)$

Change in clinical practice $(n$ $=50)$

Looking forward $(n=11)$

Studying online $(n=10)$

\section{$\underline{\text { Pre-course }}$}

\section{$\underline{\text { Concerns }}$}

Personal $(n=14)$

Time and Workload $(n=11)$

Academic $(n=11)$

Technology $(n=10)$

\section{During course} implementation

\section{Survey feedback after} completion of each module

Positive

Negative
Improve exercise prescription skills $(\mathrm{n}=33)$

New knowledge $(\mathrm{n}=19)$

Broaden or deepen knowledge $(\mathrm{n}=8)$

Develop evidence-based knowledge $(\mathrm{n}=14)$

Multidisciplinary learning $(n=6)$

Complete course $(n=1)$

Connecting with others $(n=19)$

Improve confidence $(n=8)$

Patient benefit $(n=14)$

Career benefit $(n=13)$
Personal circumstances $(n=9)$

Communication $(n=4)$

Personal ability $(n=10)$

Lack of evidence base $(n=1)$

Internet $(n=7)$

Online learning $(n=3)$

Online nature of course

Support

Relevance of material covered

Time or workload

Online nature of course

Practical classes required 


\section{Pre-course Expectations.}

The following themes emerged for pre-course expectations: learning, achievement, change in clinical practice, and looking forward and studying online themes.

Learning. Within the learning theme, identified subthemes were to improve skill at exercise prescription, to learn new knowledge, to broaden or deepen knowledge, to develop evidence-based knowledge, and to learn from the multidisciplinary student base. Detailed analysis of this theme revealed a focus on learning exercise prescription as a skill through the acquisition of knowledge. The subtheme of improving exercise prescription skills was often cited with reference to clinical populations and students expressing a lack of confidence in this area. This finding indicates that the students did not feel confident prescribing exercise to certain patient populations.

My main interest and expectation surrounding the course would be to develop knowledge and confidence regarding the prescription of exercise for the prevention and treatment of chronic diseases.

The second-most prominent subtheme was to acquire new information. Students expressed an expectation of learning about exercise prescription in clinical populations that could be helpful in their clinical settings. For example:

I plan to develop a specific area of my practice, namely health promotion in the over $60 \mathrm{~s}$, and I believe a more in-depth understanding of the effect of exercise will help me to deliver a quality service to my clients.

The third subtheme, broaden or deepen current knowledge, was highlighted through students curiosity to learn about the new research emerging in the area of exercise prescription: "I am hoping to learn the latest research and methods in prescribing exercise as a physiotherapy intervention." Results clearly show that healthcare professionals expected this course to have a strong evidence base.

The final learning subtheme was to learn from the multidisciplinary student body. One student remarked: "I'm looking forward to learning from the many different backgrounds and disciplines that has already been posted here." Research has shown that teamwork and collaboration between all health professionals is essential for high quality patient care (Chaboyer \& Patterson 2001; McPherson et al., 2001). It is encouraging to see a desire for multidisciplinary learning extending into online opportunities for continued professional development.

Achievement. The second-most referenced "expectations" theme was identified as achievement. Upon commencing the online certificate, students were expecting to be able to connect with academic staff and their classmates, as well as sharing their knowledge beyond the classroom environment. Furthermore this was something that they were clearly looking forward to. Comments that highlight this theme include:

I'm looking forward to meaningful discussions with fellow course mates and clinical educators so as to learn from their experiences and expertise

One student in particular expressed this theme very succinctly, stating that they: "Can't wait to chat to you all and learn from other people's experiences." This theme highlights the fact that students expected to interact with each other despite the online nature of the course which may traditionally have been considered to be more isolated than traditional face-to-face teaching. 
The second subtheme relating to achievement was to simply complete the course. This theme seemed to stem from the concern of having not engaged in formal education for some years. For example, one student remarked that their expectation of themselves was to "get through the course after years working in the clinical environment." This theme is of particular importance in postgraduate clinical education and highlights the fact that clinicians may regularly take part in different forms of continued professional development and still perceive formal education as a significant personal challenge. Although personal barriers such as family commitments, resistance from peers, and time constraints (French \& Dowds, 2008) have been identified in the literature, the challenge of returning to formal education after a large temporal gap in completing undergraduate education has previously not been identified in this space (see O'Donnell et al. [2009] for a discussion of this theme within the social science discipline).

Change in clinical practice. The third theme to emerge from student expectations was that of changes to clinical practice. Students expected to change their clinical practice through introducing or improving exercise prescription. The subthemes in turn were to benefit patient health and develop their own career. The caring nature of healthcare professionals was evident in this theme with the most referenced subtheme being that of expected benefits to patient health. For example, one student stated:

I was drawn to this postgraduate certificate as I have a special interest in rehabilitation and believe that as clinicians we should lead the way in improving quality of life for individuals through exercise especially for those with chronic conditions who find it more difficult and lack the confidence to exercise safely.

Results indicate that students expected the changes they made to result in improved outcomes for their patients. For example one student remarked:

We know as clinicians why patients need to engage in exercise, I hope this course will deepen my own understanding of the subject. I anticipate that in turn, this theoretical knowledge will inform my practice and help me to have more positive outcomes with service users. My goal is to effect long term change in the lifestyles of my patients, thereby improving their current physical and mental health, life expectancy and prognosis

Students also expressed an expectation that the course may benefit their careers:

Due to unforeseen circumstances I was away from work for a significant time so I have decided that undertaking this particular ... online course would be an essential step forward to refresh and regain my career ambition.

Looking forward and studying online themes. The final two themes which emerged from student expectations were looking forward and studying online. Students expressed positive expectations regarding studying online: "I am excited by the online interactive setup of this post grad certificate" and "It is my first time pursuing online education and I'm enjoying the format so far."

\section{Pre course Concerns.}

Before course teaching began, students were asked to voice their concerns about the course in their online learning journals. Four main themes emerged, which are listed in Table 2: personal concerns, academic concerns, time management and workload, and technology. 
Personal concerns. As with any student body, those taking the online postgraduate certificate in clinical exercise had concerns around the theme of balancing their personal and academic lives. Many of the students were working full time in clinical environments and also had family commitments.

Organisational skills with regard to all the weekly tasks is my main concern at present, making sure that I can keep up with all the reading requirements and also keep family life as sane as possible.

My biggest concern about taking on this post graduate study is that it will take away from quality time with my 14 month old.

Several students also expressed concern over being able to express themselves and their opinions concisely.

Another concern that I have is around my reflective writing skills. I am very good at reflecting in my head and verbally but have struggled in the past to get it down on paper succinctly. I feel that as a result I have lost some confidence in this area so this will be a good challenge for me.

Academic concerns. Students expressed concern about engaging in an academic course. Some had not been engaged with formal education for several years:

However, regarding my initial concerns-the main one is that it has been over 10 years since I have had to do any scientific or academic writing, and I am nervous about my ability to research and access material, and reference it accurately.

This is similar to the theme of achievement where students expressed a wish to complete the course. On further examination of this theme, academic writing in particular was stipulated by students as a concern.

The second subtheme with regards to academic concerns was expressed by only one student; however, it is important to note. This student in question was concerned that the body of evidence and learning material available would not meet their academic needs. This reflects the fact that the area of clinical exercise prescription is a complex and ever-evolving one.

My main concern is that I am expecting that their [sic] will be research that will allow my [sic] to prescribe exercise intensities based on specific physiological processes, or biological changes that in turn decrease the patients symptoms. I am in some way expecting that these levels will be physiologically measurable and patient specific. I think that I will find that the research is lacking in this area, and will ultimately be disappointed by this.

Unfortunately, there are frequently times when the research to date is not capable of answering specific clinical questions. This student's concerns highlights the fact that we do not yet have all the answers in the area of exercise prescription, but that in a learning environment we can share our concerns and questions and strive to make informed evidence based decisions in clinical care with available resources.

Time management and workload. The third main theme to arise from students' concerns is related to, but distinct from the first two. Students were concerned about their ability to manage time and achieve the workload expected of the postgraduate certificate in clinical exercise. Although this was not the most referenced concern, it was cited as the main concern by some students which emphasizes its importance. For example: "The main concern I have for this course 
is the amount of time and dedication it will take to achieve a high mark" and "My main challenge will be managing my time effectively."

Technology. The final theme to emerge was that of technology. Some students were concerned about their internet connection while others expressed some apprehension about the online nature of the course and their ability to engage with a course delivered entirely on an online platform. Ireland has a large rural community. One advantage of online learning is that students don't have to make long journeys to cities to avail of learning opportunities. However, there are also potential shortcomings related to connectivity: "There have been some teething problems, namely internet access, as I live in a very rural area with no high speed or fibre optic broadband connection." In healthcare, learning as part of a group has been shown to have significant advantages (McPherson et al., 2001), whether this could be achieved through an online format was a source of concern for one student:

While I am enjoying the online format, it will be unusual to not be in a physical classroom with real live classmates. The Collaborate forum is surprisingly personal though, and I do think we will get to know each other as the year goes on.

Learning online is a skill in itself, and therefore ample orientation is required, especially for those who are concerned about their ability to navigate an online learning platform or those who may feel uncomfortable contributing to one, this concern was expressed by some students:

While I was somewhat apprehensive starting an online course, it had more to do with my previous experience than the fact I am not techie enough for it all to go smoothly. So far, things have gone great and I have managed to be introduced to the online platform and even engage, as I am now doing.

\section{During course: Feedback.}

Table 3 outlines results of the quantitative survey analysis. Overall results show that students considered topics covered during online modules met learning objectives and learning outcomes to a good or very good standard. As a group, students considered the number of lectures as "just right." The vast majority of students, approximately $90 \%$ of survey responders, felt that the organization of lectures and module timetables were organized or very organized and over $90 \%$ felt that learning materials provided were either good or very good. Overall modules were rated as being either good or very good.

The final question on the survey was open-ended and simply asked students to contribute any comments or suggestions related to the module. These answers were analyzed for all modules and results are categorized into positive and negative comments. 
Table 3

Results of Post Module Surveys

Question and response options

Average

overall $(\%)$

Q1: To what standard did the topics covered meet the objectives and

learning outcomes stated in the course handbook?

Very good

58

Good

40

Average

0

Poor

0

Very poor

0

I am unaware of the learning outcomes in the handbook

0

Unanswered

2

Q2: Was the number of lectures sufficient to meet the course objectives and learning outcomes?

Too many 3

Just right $\quad 80$

Too few 17

I am unaware of the learning outcomes in the handbook 0

Unanswered

0

Q3: How do you rate the organisation of lectures and timetabling for this

module including availability of resources on Blackboard

Very organised

37

Organised

53

Average

11

Not organised

0

Very poorly organised

0

Unanswered

0

Q4: How do you rate the learning material (from presentations to webinars) provided during the module?

$\begin{array}{cc}\text { Very good } & 51 \\ \text { Good } & 44 \\ \text { Average } & 4 \\ \text { Poor } & 0 \\ \text { Very poor } & 0 \\ \text { Unanswered } & 0\end{array}$

Q5: How would you evaluate the overall module?

$\begin{array}{cc}\text { Very good } & 58 \\ \text { Good } & 39 \\ \text { Average } & 0 \\ \text { Poor } & 3 \\ \text { Very poor } & 0 \\ \text { Unanswered } & 0\end{array}$


Positive themes. Subthemes that emerged from positive comments related to the relevance or applicability of the learning material to student's clinical environments, and personal interest. For example: "All in all this module was highly informative and topics for example re limiting sedentary behaviour were adaptable in most situations for us as healthcare professionals, even pregnancy!" and "I'm looking forward to reading those articles for personal interest and guidance."

Online delivery. Students also commended the online nature of the course and its organization with comments such as: "Excellent module well presented and organised" and

I have to say there is massive benefits to education when you don't have to get into a car or public transport and race to ... your lectures. I am really enjoying this element of flexibility. So I can just log off right now and finish doing what I was earlier - technology is great!

Quality of online learning content. The quality of the online content was also highlighted as a strength of the course: "The online material provided is excellent."

Support. The final positive theme to emerge from the anonymous survey was that of support. Students felt engaged and supported throughout their learning journey online. This is reflected in comments such as: "Thanks for the motivation everyone in posting all your discussions, I was thinking that i wouldn't have a chance to complete these tasks this week but you all spurred me on!!" and "I am really enjoying the content and engagement with lecturers and other classmates."

Negative themes. Negative comments were also collated. Subthemes that emerged echoed some of the main concerns expressed by students before starting the course. The most referenced negative comment related to time management and workload.

Time management and workload. Some students felt that the workload was too much: "I have found the amount of material to pre-read and the level of exercises in the pre read a lot along with the assessments which seem to leave little time to breath with doing ordinary work and life" and "The workload was very heavy...All very relevant and interesting but hard to keep up with everything" while one felt that more learning material was needed: "I actually expected the lectures to be more in depth in terms of physiology and how it affects exercise."

Online delivery. There were also negative comments regarding the online nature of the course, in particular the lack of any practical teaching. One student remarked: "A disadvantage of the online format was evident for this module as a session in a lab or gym would make facilitate better understanding of the concepts" while another stated that "Some practical sessions would be invaluable." A suggestion on how to address this issue was also provided with one student commenting that "... one weekend module where one can see exercise testing and a few different types of exercise prescription in action would be a great addition and ideally a follow on practical module :)."

Technical difficulties. Finally, one student had technical difficulties that resulted in a negative experience and that were considered to be a problem specific to online learning as it would not have happened in a face-to-face situation:

I have been very unfortunate to have my MCQ crash twice during this module which was really very upsetting at the time when I was all geared to take the exam and on both occasions [sic] disrupted my work day. This would not happen in a sit down exam. 


\section{Limitations}

A notable limitation of this study is that only one course was analyzed. It is possible that courses of a different nature would require different student supports and result in different online student experiences. Data presented in this paper is in relation to a postgraduate health sciences course and therefore may not be applicable to undergraduate or other postgraduate courses/students. However, although data was taken from a specific course, case studies such as these can enrich the literature on healthcare student experiences in a virtual learning environment, help improve teaching methods, and ultimately ameliorate student experiences. Another limitation to this paper is that although post-module analysis was gathered, there was no detail on overall course experience gathered from students after completion of the entire course.

\section{Discussion}

Recent years have seen a surge in the number of online courses offered to healthcare professionals. Courses being offered online come with the advantage of offering clinicians more flexibility in reaching their continued professional development goals and have been reported as successfully leading to improvements in both knowledge and skill (Bello et al., 2005; Hopper \& Johns, 2007; Hugenholtz et al., 2008; Rohwer et al., 2013). This paper details the expectations, concerns, and experience of 19 students enrolled on an online postgraduate certificate in Clinical Exercise.

Ten general recommendations are proposed as supplemental material to this paper based on the analysis carried out and the experience of the researchers involved. Understanding students' expectations and concerns as they begin an online course can greatly help academic staff to tailor the learning experience in a way that supports students in reaching their learning goals.

The most prominent theme to emerge regarding students' expectations of the course was that of learning and gaining or deepening knowledge. This highlights the fact that healthcare professionals may not feel confident in exercise prescription (Hayes, 2009; Heath \& Stuart, 2002), despite a large amount of evidence that has proven exercise to be an effective treatment method for many clinical conditions that healthcare professionals may encounter on a daily basis. The gap in knowledge expressed by students may stem from the fact that much of the evidence in this area is new. It is likely that when many of the students on this course graduated, the role of exercise as a treatment tool for those with cancer, depression, communicable diseases, and other such conditions was not part of their curriculum. This is not a fault of any curriculum per se but highlights the need for continued professional development in areas where research is evolving rapidly. This finding highlights the opportunity for online courses to be used to keep professionals up to date on evolving research in their area.

What is perhaps most interesting about the student expectations was that students expressed an expectation that the knowledge gained would lead to an improvement in their prescription skills. It has been shown that fully online courses imparting knowledge can lead to an improvement in clinician skills (Bello et al., 2005; Edrich et al., 2016; Rohwer et al., 2013).

It is important for academic staff to be aware of concerns that students have as they engage in further education. The flexibility afforded by online learning enables students who would be unable to attend traditional face-to-face teaching to engage in formal and informal education. However, the physical ability to log on and participate in a course does not remove other barriers 
to further education, such as family and work commitments (Muilenburg \& Berge, 2005; Sorensen \& Donovan, 2017). This was evident from the results of the current study where students were positive about the online nature of the course but concerned about their ability to fully engage with and complete the course due to their personal commitments.

High dropout rates are often reported in online courses (Bawa, 2016). The reasons for such high dropout rates are often unclear since the students of interest are those who are no longer engaging with the course (Fetzner, 2013). However, results of this study give some insight into the concerns and difficulties expressed by online learners. Students were concerned about the workload and time commitment that the course would require. In line with this concern, some students reported in the post-module surveys that the course had a heavy workload. This issue may be indirectly related to the online nature of the course whereby students were able to continue working clinically full time due to the flexibility provided by the online course, whereas with faceto-face teaching they would likely have had to reduce their working hours to attend classes during working hours.

Another concern was students' ability to express themselves. This concern was at times linked to the fact that the course was online. Some students were anxious about their ability to navigate and engage with the online platform. A greater concern, however, seemed to be the ability to meet academic standards. This stemmed from the fact that many students had not taken part in formal education for a number of years. It is possible that the online nature of this course finally afforded them an opportunity to do so.

Results of post-module surveys showed students highly rated the teaching resources and found them to be relevant and informative. All four modules were rated as being good or very good. Learning material seemed to appeal to students' clinical/professional as well as their personal interest. Since the majority of students would have been working in a specific clinical area (e.g., mental health, cardiovascular medicine or a community setting) it is assuring that material which may not have been directly related to their speciality was viewed positively and enjoyed. The online nature of the course was also received positively.

Feedback from the post module surveys also revealed limitations to this course. Most notably, students expressed a desire to have a practical teaching session. This finding highlights the limitation of online learning in the area of clinical exercise and has been previously expressed by students studying anatomy and physiotherapy-specific courses online (Harvey et al., 2014; Swinnerton et al., 2016). Previous research has shown no difference in the course results of students who engage with course material online compared to those who engage in the traditional face-to-face method (Bello et al., 2005; Cook \& Steinert, 2013; Edrich et al., 2016; Matzie, 2010; Pourmand et al., 2013). However, studies have also shown that a blended learning approach where both methods are used could leverage even better results (Edirippulige et al., 2012; Eksteen, 2011). The examination of a blended learning approach was beyond the scope of this study.

Many, but not all, courses involving the acquisition of skills have taken a blended learning approach, combining both traditional and e-learning methodologies in order to optimise face-toface time to impart skills. While the literature would suggest that blended learning is effective at undergraduate level, students at postgraduate level can be successful at enhancing both their knowledge and practical skills through online learning alone (Rohwer et al., 2013). Few studies have examined the efficacy of teaching clinical skills through e-learning alone. Of those that have, Edrich et al. concluded that web-based training was just as effective as traditional methods at 
teaching anaesthesiologists lung ultrasound skills (Edrich et al., 2016), and Roesch et al. advocated a computer assisted learning program for the provision of both theoretical biomedical knowledge and clinical skills in the area of dermatology (Roesch et al., 2003). Other studies have shown positive results from teaching airway management (Bello et al., 2005) and paediatric rheumatology (Manners, 2013) fully online.

Investigating the concerns, expectations, and experience of a cohort of online postgraduate students in clinical exercise has contributed valuable knowledge to the discipline. Understanding key themes can support future development in online modules in this space, and has added to the body of literature on online learning within the health sciences. It appears that overall students were highly appreciative of the learning resources available to them in an easily accessible and flexible format, the quality of teaching, the support received by peers as well as teaching staff, and the relevance of the material presented to their clinical settings and learning goals. The online nature of the course was perceived as a challenge by some students and not without its limitations. However, students also saw it as an advantage and as something which enabled them to reach their learning goals despite work and family commitments.

Overall analysis of the findings presented in this paper provide evidence for the success of teaching clinical exercise online. However, it should also be noted the workload may be perceived as heavy for students who choose to continue to work full time and there may be a need to support some online learning in practical subjects with face-to-face practical teaching sessions. Online learning results in student expectations and concerns that are unique to the VLE. The evidencebased recommendations provided as supplemental material to this paper may help online clinical educators and students to maximize the success of their teaching and learning experiences, respectively. 


\section{References}

Allen, E., Seaman, J., Poulin, R., \& Taylor Straut, T. (2016). Online report card: Tracking online education in the United States. Babson Survey Research Group and Quahog Research Group. http://onlinelearningsurvey.com/reports/onlinereportcard.pdf

Ally, M. (2004). Foundations of educational theory for online learning. Athabasca University Press. http://stoa.usp.br/ewout/files/1073/6047/TerryAndersonEntireBook.pdf.

Anaf, S., \& Sheppard, L. (2010). Lost in translation? How patients perceive the extended scope of physiotherapy in the emergency department. Physiotherapy, 96(2), 160-168.

Bawa, P. (2016). Retention in Online Courses: Exploring Issues and Solutions-A literature review. Review, SAGE Open, 6(1). https://doi.org/10.1177/2158244015621777

Bello, G., Pennisi, M. A., Maviglia, R., Maggiore, S. M., Bocci, M. G., Montini, L., \& Antonelli, M. (2005). Online vs live methods for teaching difficult airway management to anesthesiology residents. Intensive Care Medicine, 31(4), 547-552.

Bergold, M., Strametz, R., Weinbrenner, S., Khan, K. S., Zamora, J., Moll, P., \& Weberschock, T. (2013). Evidence-based Medicine online for young doctors-a randomised controlled trial. Zeitschrift für Evidenz, Fortbildung und Qualität im Gesundheitswesen, 107(1), 36-43.

Blundell, A., Gordon, A. L., Masud, T., \& Gladman, J. (2011). Innovations in teaching undergraduates about geriatric medicine and ageing-results from the UK National Survey of Teaching in Ageing and Geriatric Medicine. European Geriatric Medicine, 2(1), 12-14.

Brown, M., \& Bullock, A. (2014). Evaluating PLATO: Postgraduate teaching and learning online. The Clinical Teacher, 11(1), 10-14.

Chaboyer, W. P., \& Patterson, E. (2001). Australian hospital generalist and critical care nurses' perceptions of doctor-nurse collaboration. Nursing \& Health Sciences, 3(2), 73-79.

Cook, D. A., \& Steinert, Y. (2013). Online learning for faculty development: A review of the literature. Medical Teacher, 35(11), 930-937.

Costello, E., Corcoran, M. A., Barnett, J. S., Birkmeier, M. C., Cohn, R., Ekmekci, O., ... \& Walker, B. (2014). Information and communication technology to facilitate learning for students in the health professions: Current uses, gaps, and future directions. Online learning: Official Journal of the Online Learning Consortium, 18(4). doi:10.24059/olj.v18i4.512

Dennis, J. M. P., J.S. and Chuateco, L.I. (2005). 'The Role of Motivation, Parental Support, and Peer Support in the Academic Success of Ethnic Minority First-Generation College Students.' Journal of College Student Development 46. doi: 10.1353/csd.2005.0023

Edirippulige, S., Smith, A. C., Armfield, N. R., Bensink, M., \& Wootton, R. (2012). Student perceptions of a hands-on practicum to supplement an online eHealth course. Journal of Medical Internet Research, 14(6). doi:10.2196/jmir.2029

Edrich, T., Stopfkuchen-Evans, M., Scheiermann, P., Heim, M., Chan, W., Stone, M. B., ... \& Szabo, A. L. (2016). A comparison of web-based with traditional classroom-based training of lung ultrasound for the exclusion of pneumothorax. Anesthesia \& Analgesia, 123(1), 123128. 
Eksteen, C. (2011). Blended teaching strategies in physiotherapy to optimize variety learning in students. Physiotherapy, 97(SUPPL), 1 -eS1476.

Elo, S., \& Kyngäs, H. (2008). The qualitative content analysis process. Journal of Advanced Nursing, 62(1), 107-115.

Field, T. (2002). Internet-based education for enrolled nurses: Could it be e-ffective? Australian Journal of Advanced Nursing, 19(4), 33.

Fetzner, M. (2013). What do unsuccessful online students want us to know? Online Learning, 17(1). doi:10.24059/olj.v17i1.319

French, H. P., \& Dowds, J. (2008). An overview of continuing professional development in physiotherapy. Physiotherapy, 94(3), 190-197.

Gardner, P., Slater, H., Jordan, J. E., Fary, R. E., Chua, J., \& Briggs, A. M. (2016).

Physiotherapy students' perspectives of online e-learning for interdisciplinary management of chronic health conditions: a qualitative study. BMC Medical Education, 16(1), 62.

Gilly, S. (2013). E-tivities: The Key to Active Online Learning. New York, Routledge.

Gummesson, C., \& Nordmark, E. (2012). Self-reflections in an online course-Reflecting learning strategies? Advances in Physiotherapy, 14(2), 87-93.

Harvey, L. A., Glinsky, J. V., Lowe, R., \& Lowe, T. (2014). A massive open online course for teaching physiotherapy students and physiotherapists about spinal cord injuries. Spinal Cord, 52(12), 911.

Hayes, S. C., Spence, R. R., Galvão, D. A., \& Newton, R. U. (2009). Australian Association for Exercise and Sport Science position stand: Optimising cancer outcomes through exercise. Journal of Science and Medicine in Sport, 12(4), 428-434.

Haywood, H., Pain, H., Ryan, S., \& Adams, J. (2013a). The continuing professional development for nurses and allied health professionals working within musculoskeletal services: a national UK survey. Musculoskeletal Care, 11(2), 63-70.

Haywood, H., Pain, H., Ryan, S., \& Adams, J. (2013b). Continuing professional development: Issues raised by nurses and allied health professionals working in musculoskeletal settings. Musculoskeletal Care, 11(3), 136-144.

Heath, J. M., \& Stuart, M. R. (2002). Prescribing exercise for frail elders. The Journal of the American Board of Family Practice, 15(3), 218-228.

Hopper, K. B., \& Johns, C. L. (2007). Educational technology integration and distance learning in respiratory care: practices and attitudes. Respiratory Care, 52(11), 1510-1524.

Howland, J. L., \& Moore, J. L. (2002). Student perceptions as distance learners in Internet-based courses. Distance Education, 23(2), 183-195.

Hsieh, H. F., \& Shannon, S. E. (2005). Three approaches to qualitative content analysis. Qualitative Health Research, 15(9), 1277-1288.

Hugenholtz, N. I., De Croon, E. M., Smits, P. B., Van Dijk, F. J., \& Nieuwenhuijsen, K. (2008). Effectiveness of e-learning in continuing medical education for occupational physicians. Occupational Medicine, 58(5), 370-372. 
Lefmann, S. A., \& Sheppard, L. A. (2014). Perceptions of emergency department staff of the role of physiotherapists in the system: a qualitative investigation. Physiotherapy, 100(1), 86-91.

Mącznik, A. K., Ribeiro, D. C., \& Baxter, G. D. (2015). Online technology use in physiotherapy teaching and learning: a systematic review of effectiveness and users' perceptions. $B M C$ Medical Education, 15(1), 160.

Manners, P., \& Guttinger, R. (2013). FRI0333 The online graduate certificate of paediatric rheumatology UWA (grad cert prheum): An evaluation. Annals of the Rheumatic Diseases, $71,426-427$.

Matzie, K. A., Philbrook, L., Mitani, A., Lipsitz, S., Gerhard-Herman, M., Pozner, C., \& Frendl, G. (2010). Comparison of web-based and classroom-based training programs for point-of care, real-time ultrasound-guided central venous catheter placement. American Journal of Respiratory and Critical Care Medicine, 181. http://doi.org/10.1164/ajrccmconference.2010.181.1_MeetingAbstracts.A5535

McDonald, P. L., Lyons, L. B., Straker, H. O., Barnett, J. S., Schlumpf, K. S., Cotton, L., \& Corcoran, M. A. (2014). Educational mixology: A pedagogical approach to promoting adoption of technology to support new learning models in health science disciplines. Online Learning: Official Journal of the Online Learning Consortium, 18(4). doi:10.24059/olj.v18i4.514

McPherson, K., Headrick, L., \& Moss, F. (2001). Working and learning together: Good quality care depends on it, but how can we achieve it? BMJ Quality \& Safety, 10(suppl 2), ii46ii53.

Moore, A., Morris, J., Crouch, V., \& Martin, M. (2003). Evaluation of physiotherapy clinical educational models: Comparing 1: 1, 2: 1 and 3: 1 placements. Physiotherapy, 89(8), 489501.

Muilenburg, L. Y., \& Berge, Z. L. (2005). Student barriers to online learning: A factor analytic study. Distance Education, 26(1), 29-48.

Murphy, J., Worswick, L., Pulman, A., Ford, G., \& Jeffery, J. (2015). Translating research into practice: Evaluation of an e-learning resource for healthcare professionals to provide nutrition advice and support for cancer survivors. Nurse Education Today, 35(1), 271-276.

O'Donnell, V. L., Tobbell, J., Lawthom, R., \& Zammit, M. (2009). Transition to postgraduate study: Practice, participation and the widening participation agenda. Active Learning in Higher Education, 10(1), 26-40.

Pourmand, A., Lucas, R., \& Nouraie, M. (2013). Asynchronous web-based learning, a practical method to enhance teaching in emergency medicine. Telemedicine and e-Health, 19(3), 169-172.

Roesch, A., Gruber, H., Hawelka, B., Hamm, H., Arnold, N., Popal, H., ... \& Stolz, W. (2003). Computer assisted learning in medicine: A long-term evaluation of the "Practical Training Programme Dermatology 2000." Medical Informatics and the Internet in medicine, 28(3), $147-159$. 
Rohwer, A., Young, T., \& Van Schalkwyk, S. (2013). Effective or just practical? An evaluation of an online postgraduate module on evidence-based medicine (EBM). BMC Medical Education, 13(1), 77.

Song, L., Singleton, E. S., Hill, J. R., \& Koh, M. H. (2004). Improving online learning: Student perceptions of useful and challenging characteristics. The Internet and Higher Education, 7(1), 59-70.

Ruckert, E., McDonald, P. L., Birkmeier, M., Walker, B., Cotton, L., Lyons, L. B., ... \& Plack, M. M. (2014). Using technology to promote active and social learning experiences in health professions education. Online Learning, 18(4). http://dx.doi.org/10.24059/olj.v18i4.515

Sorensen, C. \& Donovan, J. (2017). An examination of factors that impact the retention of online students at a for-profit university. Online Learning, 21(3), 206-221.

Swinnerton, B. J., Morris, N. P., Hotchkiss, S., \& Pickering, J. D. (2017). The integration of an anatomy massive open online course (MOOC) into a medical anatomy curriculum. Anatomical Sciences Education, 10(1), 53-67.

Tan, S., Ladyshewsky, R., \& Gardner, P. (2010). Using blogging to promote clinical reasoning and metacognition in undergraduate physiotherapy fieldwork programs. Australasian Journal of Educational Technology, 26(3), 355-368.

Wolbrink, T. A., \& Burns, J. P. (2012). Internet-based learning and applications for critical care medicine. Journal of Intensive Care Medicine, 27(5), 322-332. 


\section{Appendix A: Recommendations}

Each recommendation below was informed by results derived from this study, however they have been developed to reflect general situations in an attempt to be useful to those teaching in other subject areas and with other student bodies.

Recommendation

Explanation

1: Inter-professional learning should be encouraged between students

\section{2: Do not limit learning outcomes to the acquisition of knowledge - strive to encourage students to apply this knowledge and develop practical skills}

\section{3: Support evidence based learning with digital resources and online orientation of web-based learning materials}

In this study students had positive expectations about learning from each other, especially those in other health care disciplines. In medical education, inter-professional learning is encouraged at all levels. Results of this paper suggest that qualified professionals expect to be able to learn from each other, even in an online format, and are positive about sharing knowledge across disciplines. Students also expressed a desire to get to know one another. In this course, students were provided with discussion boards, blogs and virtual rooms which they were encouraged to use as informal spaces to discuss course material and share views.

The expectation that the knowledge gained would lead directly to skill acquisition was interesting since the course offered was fully online. This shows how students have an expectation to directly apply knowledge gained in their work place. This finding is encouraging and supports previous research which has demonstrated the ability for health care professional to acquire practical skills through online learning. This may be particularly relevant at postgraduate level where students already possess a clinical skill set and interact with patients on a daily basis.

In line with best practice, it is advised that online courses are evidence based. Results of this study indicated that students expected information presented to be heavily evidence based. It can be argued that the online space is well equip to present information in an evidence based fashion. Active links can be provided to reference texts, ensuring students have easy and quick access to relevant sources of information. From the authors experience running this course, it is recommended that students are provided with digital resources including journal articles and e-books, and that this material is easily accessible within the course learning platform. It is also recommended that students are familiarised with the electronic databases and how to use them, as well as electronic libraries (where available) prior to commencing the course. Despite the majority of students living within easy reach of the college's physical library, anecdotal evidence suggests that digital resources were used by all students as primary resources, over the physical 
library. All students were obliged to attend an hour long orientation of the electronic library prior to commencing the course. During this time lead academics demonstrated how to use electronic databases and the college's electronic library. It is recommended that ample time be given to orientation and familiarisation with the learning platform including any digital resources that are available in order for students' to gain the most from the course material.

4: Provide flexible student supports

\section{5: Be cognisant that} online students may also be working full time and therefore perceive the course workload as 'heavy'
Despite initial concerns, students reported feeling supported by their class and academics teaching on the course. This is important as lack of support can be a barrier to online learning (Muilenburga 2005). Support was provided formally by academic staff in the form of open office hours, whereby a member of staff was present in an online room during specific times each week. Students did not need an appointment, but could simply access this room to speak with the academic during the allocated time. Students were also encouraged to email or ring academic or technical staff if they encountered any problems. Furthermore, being fully registered, online students could avail of the same college supports as any other student including their student union, medical and counselling services. Of all the services and supports that were put in place, students typically stated encouragement they received from one another through discussion posts as a valued source of support. Peer support is highly valued in university settings (Dennis 2005). This study illustrated that it is also possible to garner peer support informally in an online course.

Online learning provides a flexibility of learning, however it is subject to the same academic rigour and structures as face to face teaching. As such the online Certificate in Clinical Exercise carried the same number of credits, or workload, as other certificate courses. This uniform workload may have been perceived as 'heavy' by those who choose to remain in full time employment. It is important to highlight the expected workload of the course prior to student's enrolling. The authors encourage a realistic approach to this issue. Online education affords flexibility to students and while students can 'catch up' on material they missed during periods where they could not dedicate time to the course, the authors suggest that there is a limit to this flexibility. For example, students may be awarded a small number of credits to be present during live webinars (online classes), and assignments set during the course should be submitted by a pre-determined date before the course ends. These arrangements reflect traditional face to face teaching and render it impossible to complete the entire course in a very short space of time. 
6: Those who have had a break in their formal education may need additional support.

\section{7: Provide resources on writing skills}

\section{8: Clearly outline time commitments}

\section{9: Consider blended learning}

Several students expressed concern over having not engaged in formal education for many years. It is recommended that at the beginning of a course students are supported and encouraged heavily and that as the course progresses this support can be reduced. It is worth noting that those students who expressed concern over a gap in their education performed very well academically. This experience can be used to encourage other students in similar situations who are concerned about re-entering formal education.

Interestingly, students expressed concern about their writing skills. It is important to note that academic writing is not a requirement of continued professional development. Resources to aid students with their academic writing can easily be put in place to support students and address this concern.

A key concern students had before they commenced this course, which remained an issue throughout the course, was time management. It is recommended that a detailed timetable is provided to students before they commence the course and that the number of hours of expected engagement with the course are outlined before students begin. The degree of flexibility should also be detailed. For example in some online courses students can engage with the material in their own time (for example at the weekend) while in others there is a requirement to be online at a given time. The level and structure of the engagement required for the course should be clearly specified before students enrol to enable them to realistically determine whether they can afford the time needed to undertake the course. One method could be to ask students to create a timetable of their usual week and determine whether they can dedicate the required number of hours to the course before they begin.

Feedback from this course suggested that a practical element may have been helpful to students. Blended learning combines online with face to face teaching and has been well received by both students and staff in the field of medical education (Eksteen 2011, Gardner et al. 2016). It should be noted that students felt the need for a practical component of the online course rather than the course being delivered completely in the traditional face to face method. Students also felt that very little practical teaching would be required, with one student suggesting a weekend would suffice, and another mentioning a single practical session. This finding is noteworthy, especially since students felt that the learning materials were of a high quality and that course learning objectives were met. 
10: Learning online is a skill in itself - let students know this so that they allow themselves time to acquire it
For students who are nervous about learning in an online environment it is worth letting them know that learning to be an online learner will take some time and effort but that it is a life skill in itself. Once they are competent in the VLE they will then be equipped with the skills needed to engage with other online resources, for example professional society blogs and learning spaces online. A student does not have to be a 'techie' to be an effective and efficient online learner, however they do need to set aside some time to acquire the necessary skills. Course coordinators should consider students becoming online learners as a goal of their courses and work this into the course orientation time. The model we used to support students in becoming independent online learners was the five stage model by Professor Salmon (Gilly 2013). 